\title{
Studies on patient's perception and awareness of health insurance coverage for smoking cessation treatment in dentistry
}

\author{
In-Woo Cho, Hyun-Seung Shin*, Jung-Chul Park \\ Department of Periodontology, Dankook University of Dentistry, Cheonan, Republic of Korea
}

Purpose: Recently, smoking cessation treatment at dental clinic can be covered by national health insurance. The aim of this study is to evaluate the awareness on the health insurance coverage for smoking cessation treatment in dentistry. Materials and Methods: The survey was carried out on 100 new patients of the patients in Dankook Dental Hospital from March to April 2015. The Questionnaire consists of 18 items. Results: The results show that many of patients expect positive effects of the treatment but most of the respondents were not aware of the initiation of health insurance coverage smoking cessation treatment in dentistry. Conclusion: The government and ministry of health should pay more attention to the promotion of the smoking cessation treatment in dentistry. (J Dent Rehabil Appl Sci 2015;31(3):195-202)

Key words: smoking cessation; heath insurance; dentistry

\section{서론}

담배에는 4000여가지 이상의 유해물질이 있으며, 이중 60 여종은 발암 물질로 분류된다. 이로 인해 인체의 여러 기관은 심각한 영향을 받게 된다. 흡연으로 야기되는 질 병 중 가장 널리 알려진 것은 폐암이며, 2014년도 통계에 따르면 한국인의 폐암 발생률은 $9.9 \%$ 로 보고되었다. ${ }^{1}$ 흡 연은 또한 심혈관계에 영향을 주어 심근경색의 위험 요 소로 작용하며, ${ }^{2}$ 근골격계에도 악영향을 주는 것으로 알 려져 있고, ${ }^{3}$ 시력 및 눈의 건강에도 해로운 것으로 밝혀 졌으며, ${ }^{4}$ 영유아 돌연사의 심각한 위험요소로 보고되고 있다. ${ }^{5}$

특히 구강은 흡연 시 담배 연기의 유해성분과 가장 먼 저 접촉하는 기관으로 각종 질병의 발생을 피할 수 없다. 흡연자는 비흡연자에 비해 구강암, 구취, 구강 건조증, 치 아 변색, 미각 상실, 구내염, 창상 지연, 구강 점막의 각화

*Correspondence to: Hyun-Seung Shin

Assistant Professor, Department of Periodontology, Dankook University of Dentistry, 119, Dandae-ro, Dongnam-gu, Cheonan, 31116, Republic of Korea Tel: +82-41-550-0261, Fax: +82-0303-3442-7364, E-mail: perioshin@dankook. ac.kr

Received: June 22, 2015/Last Revision: July 14, 2015/Accepted: July 14, 2015
와 백반증, 구강 건조증, 구순 구개열의 발생이 현저히 높 다. ${ }^{6}$ 또한 임플란트의 수명에도 악영향을 끼치며, ${ }^{7}$ 창상 지연으로 인해 치주치료의 효과가 낮아지는 것으로 보고 되었으며, ${ }^{8}$ 우리나라에서 흡연자의 치주 질환으로 발생 하는 사회적, 경제적 비용은 1 인당 연간 $16,684,269$ 원에 이르는 것으로 추산 되었다. ${ }^{9}$

흡연의 이러한 보건, 사회, 환경 및 경제적 폐해로부 터 현 세대와 미래 세대를 보호하기 위하여 국제적으로 는 2005년부터 World Health Organization (WHO)의 주도하에 Framework Convention on Tobacco Control (FCTC)이 출범되어 국가간 협상을 통한 제도적 금연 정 책이 시행되어 왔다. 우리나라에서도 1986년도에 법안 이 마련되어 담뱃갑에 경고 문구를 표기하고, 1995년에 국민건강증진법이 시행되면서 적극적인 담배 규제 정책 을 시행하고 있다.

온라인 상에서는 2001년 보건복지부와 국립암센터에 
서 ‘금연길라잡이' 라는 포탈 사이트를 개설하여 다양 한 금연정책 및 금연사업을 소개하고 흡연예방 및 금연 촉진을 위한 금연정보와 서비스를 제공하고 있다. 금연 길라잡이에서는 2004년 모바일 금연프로그램을 구축하 고, 2009년에는 4종의 인터넷 금연 게임을 구축하였으 며, 2010, 2011년에는 2개의 모바일 어플리케이션을 개 발하여 운영하고 있다.

이러한 정책적 흡연 규제 사업과 더불어 흡연자의 금 연을 돕기 위해 2005년부터 전국 250여개의 보건소에서 무료 금연상담 및 치료 서비스를 위하여 금연클리닉을 개설하였으며, 금연상담사 등의 전문 인력을 육성하였 다. 보건소 금연클리닉으로 인한 우리나라 성인 남성의 직접적인 흡연율 감소 효과는 2007년에 $0.24 \%, 2008$ 년 에 $0.18 \%$ 로 보고되었다. ${ }^{10}$

그리고 지난 2015년 2월 25일부터는 보건소 뿐만 아 니라 금연치료기관에 등록한 치과의원에서도 금연상 담, 금연치료 의약품 처방 등의 금연진료를 할 수 있도 록 국민건강보험 적용을 확대하였다. 하지만 일반적으 로 우리나라에서 정책 시행에 필요한 홍보 프로그램이 대체적으로 부족한 편이고, 홍보관리운영팀을 운영하거 나 전문가의 컨설팅을 받는 경우는 매우 드문 것이 현실 이다. 이번 금연진료 보험 확대의 경우에도 효과 여부를 떠나 정책에 관한 홍보 부족으로 인하여 흡연자들이 시 행 여부를 몰라 혜택을 받지 못하게 되지 않을까 우려되 는 바이다.

이에 본 연구에서는 최근에 시행된 치과 내 금연치료 건강보험 적용에 대한 환자 인식도 및 의식 수준을 설문 지를 바탕으로 평가하여 공공보건정책의 한계점을 분석 해보고, 아울러 바람직한 정책의 시행방안을 제시해 보 고자 한다.

\section{연구 재료 및 방법}

2015년 3월 한달간 단국대학교 치과대학 부속치과병 원에 처음 내원한 환자 100 명을 무작위로 선정하여(소 아치과 제외) 설문조사를 하였다. 설문지 문항은 단국대 학교 치과대학 부속치과병원에 근무중인 치과의사 10 명이 협의하여 개발하였으며, 개발자 중 4 명은 흡연자 였고 5 명은 비흡연자였으며, 1 명은 금연자(금연기간 1 년)이였다. 문항 내용은 인구학적 조사, 일반적인 금연 에 관한 지식 조사와, 치과 금연치료에 관한 환자의 인 식, 금연 정책에 관한 인식으로 나뉘며 총 18 문항으로
구성되었다. 설문 결과는 단일 응답 설문일 경우 백분율 (\%)로 평가 하였고, 복수 응답 설문일 경우에는 빈도분 석을 통해 백분율 $(\%)$ 로 평가하였다.

\section{결과}

\section{1. 인구학적 조사(Table 1)}

환자군의 성별 분포는 남성 $49 \%$, 여성 $51 \%$ 로 거의 같 았다. 연령층은 20 대가 $35 \%$ 로 가장 많았으며, 40 대, 30 대, 50 대 순으로 분포하였다. 혼인 상태는 기혼 $49 \%$, 미 혼 $50 \%$ 로 유사한 분포를 보였다. 직업군은 학생이 $27 \%$ 로 가장 많았으며 주부, 전문직, 사무직, 서비스업 순으 로 분포했다. 흡연자는 $18 \%$ 였고, 비흡연자는 $70 \%$ 였으 며, $12 \%$ 는 금연 중으로 평균 금연 기간은 약 2.3 년이었 다.

Table 1. Patient's demographics

\begin{tabular}{|c|c|c|c|}
\hline & & $\begin{array}{l}\text { Number } \\
(n=100)\end{array}$ & $\begin{array}{c}\text { Percentage } \\
(\%)\end{array}$ \\
\hline \multirow[t]{2}{*}{ Sex } & Male & 49 & 49 \\
\hline & Female & 51 & 51 \\
\hline \multirow[t]{7}{*}{ Age } & $10-19$ & 4 & 4 \\
\hline & $20-29$ & 35 & 35 \\
\hline & $30-39$ & 21 & 21 \\
\hline & $40-49$ & 24 & 24 \\
\hline & $50-59$ & 11 & 11 \\
\hline & $60-69$ & 3 & 3 \\
\hline & $70-$ & 2 & 2 \\
\hline \multirow[t]{2}{*}{ Marriage } & Yes & 49 & 49 \\
\hline & No & 51 & 51 \\
\hline \multirow[t]{6}{*}{ Occupation } & Student & 27 & 27 \\
\hline & House wife & 20 & 20 \\
\hline & Specialized job & 16 & 16 \\
\hline & Office job & 14 & 14 \\
\hline & Service industry & 9 & 9 \\
\hline & Etc. & 14 & 14 \\
\hline \multirow[t]{3}{*}{ Smoking status } & Smoker & 18 & 18 \\
\hline & Non-smoker & 70 & 70 \\
\hline & $\begin{array}{l}\text { Non-smoker } \\
\text { with smoking } \\
\text { experience }\end{array}$ & 12 & 12 \\
\hline
\end{tabular}




\section{2. 금연 지식 상태 조사(Table 2)}

병원에서 시행하는 금연 치료에 관한 설문에서 $52 \%$ 의 응답자가 처음 들어 보았다고 답했으며, $46 \%$ 는 내 과, 가정의학과, 보건소 등의 의료기관에서 시행하는 것 으로 알고 있었다. 병원과 치과에서 진료를 받을 수 있 다고 생각하는 응답자는 $1 \%$, 병원, 치과, 한의원에서 모 두 금연 진료를 받을 수 있다고 생각하는 응답자도 1\% 였다.
금연치료에 적합할 것으로 생각하는 의료기관에 관한 복수 응답 설문에서는 보건소가 $28.7 \%$ 로 가장 높았으 며, 종합병원(22.5\%), 치과병원(15.2\%), 가정의학과의원 $(14.6 \%)$, 내과 $(9 \%)$, 치과 $(6.2 \%)$, 한의원 $(2.2 \%)$ 순이었다.

금연치료에 효과적으로 생각하는 인력으로는 금연전 문 상담사가 $47.1 \%$ 로 가장 높았으며, 의사는 $32.5 \%$, 치 과의사는 $11.5 \%$ 로 선택되었다(복수 응답).

금연에 도움을 줄 수 있는 수단으로 생각되는 것에는 금연교육이 $32.0 \%$ 로 가장 높았으며, 담뱃값 인상, 니코 틴 패치, 보조 약물 복용, 금연 구역 확대 순이었다.

Table 2. Survey on Knowledge about non-smoking treatment

\begin{tabular}{|c|c|c|}
\hline Do you know about the smoking treatment received at the hospital? & Number $(n=100)$ & Percentage $(\%)$ \\
\hline No & 52 & 52 \\
\hline I thought I can get from hospital & 46 & 46 \\
\hline I thought I can get from hospital and dental clinic & 1 & 1 \\
\hline I thought I can get from hospital and dental clinic and oriental medical clinic & 1 & 1 \\
\hline Which institution is appropriate for smoking cessation treatment? (Multiple responses) & Number $(\mathrm{n}=178)$ & Percentage $(\%)$ \\
\hline General Hospital & 40 & 22.5 \\
\hline Dental Hospital & 27 & 15.2 \\
\hline Internal medicine clinic & 16 & 9.0 \\
\hline Family medicine clinic & 26 & 14.6 \\
\hline Public Health center & 51 & 28.7 \\
\hline Dental clinic & 11 & 6.2 \\
\hline Oriental medical clinic & 4 & 2.2 \\
\hline Etc. & 3 & 1.7 \\
\hline $\begin{array}{l}\text { Who is thought to be effective in the treatment of smoking cessation treatment? } \\
\text { (Multiple responses) }\end{array}$ & Number $(\mathrm{n}=157)$ & Percentage $(\%)$ \\
\hline Doctor & 51 & 32.5 \\
\hline Dentist & 18 & 11.5 \\
\hline Nurse & 3 & 1.9 \\
\hline Nursing assistant & 2 & 1.3 \\
\hline Dental Hygienist & 8 & 5.1 \\
\hline Professional counselor for smoking cessation & 74 & 47.1 \\
\hline Etc. & 1 & 0.6 \\
\hline Which one is thought as a means to help quit smoking? (Multiple responses) & Number $(\mathrm{n}=169)$ & Percentage $(\%)$ \\
\hline Non-smoking Education & 54 & 32.0 \\
\hline Nicotine fetch & 21 & 12.4 \\
\hline Auxiliary medicine & 19 & 11.2 \\
\hline Non-smoking acupuncture & 10 & 5.9 \\
\hline Psychological Hypnosis counseling & 13 & 7.7 \\
\hline Enlarge or non-smoking area & 18 & 10.7 \\
\hline Tobacco price raising & 29 & 17.2 \\
\hline Etc. & 5 & 3.0 \\
\hline
\end{tabular}




\section{3. 치과 금연 치료에 관한 인식 조사(Table 3)}

치과질환과 흡연의 상관성에 관해서 $95 \%$ 의 응답자 가 관련이 있다고 생각했다. 금연 진료가 치과에서 가능 하게 된 정보에 관해서는 $79 \%$ 의 응답자가 처음 들어 보
았다고 답했으며, 잘 알고 있다고 응답한 군은 $2 \%$ 에 불 과했다(Fig. 1). 치과에서 처방하는 금연 보조제, 보조 약 품에 관해서는 $86 \%$ 의 응답자가 처음 들어보았다고 답 했으며, $12 \%$ 의 응답자가 들어본 적이 있다고 답했으며, 잘 알고 있다고 응답한 군은 $2 \%$ 였다.

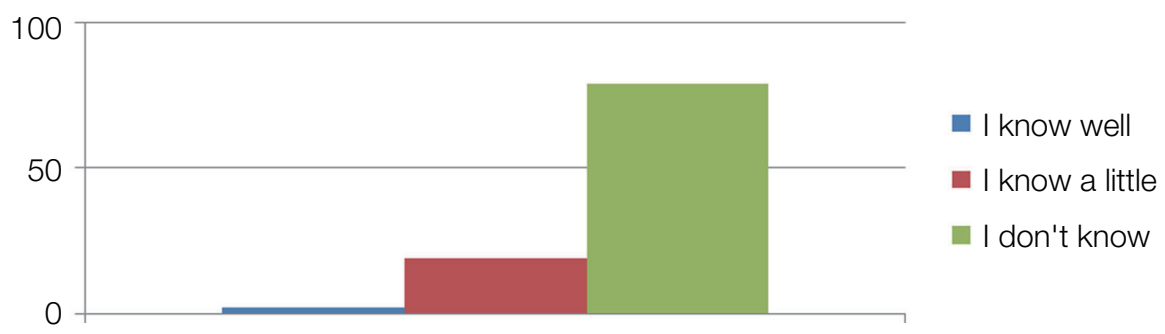

Fig. 1. Awareness about smoking cessation counseling treatment in dental clinic.

Table 3. Survey on perception about non-smoking treatment in dentistry

\begin{tabular}{|c|c|c|}
\hline Do you think smoking is associated with dental disease? & Number $(\mathrm{n}=100)$ & Percentage $(\%)$ \\
\hline Yes & 95 & 95 \\
\hline No & 5 & 5 \\
\hline Do you know about smoking cessation counseling in dental treatment? & Number $(\mathrm{n}=100)$ & Percentage $(\%)$ \\
\hline Yes, I do Well & 2 & 2 \\
\hline I have heard about it & 19 & 19 \\
\hline No, I don't & 79 & 79 \\
\hline Do you think smoking in dental treatment is effective? & Number $(\mathrm{n}=100)$ & Percentage $(\%)$ \\
\hline Very effective & 18 & 18 \\
\hline Slightly effective & 30 & 30 \\
\hline Just so & 40 & 40 \\
\hline Little effect & 7 & 7 \\
\hline No effect & 5 & 5 \\
\hline Your thoughts on the smoking cessation medication in dentistry? & Number $(n=100)$ & Percentage $(\%)$ \\
\hline Very appropriate & 20 & 20 \\
\hline Some are appropriate & 76 & 76 \\
\hline No effect & 2 & 2 \\
\hline Inadequate & 1 & 1 \\
\hline Etc. & 1 & 1 \\
\hline $\begin{array}{l}\text { Which one is necessary for the activation of dental smoking cessation treatment? } \\
\text { (Multiple responses) }\end{array}$ & Number $(\mathrm{n}=141)$ & Percentage $(\%)$ \\
\hline Emphasize the necessity of Non-smoking for oral health & 66 & 46.3 \\
\hline Dentists specialize on the treatment of smoking & 15 & 10.6 \\
\hline Active promotion that smoking cessation treatment is available for dental treatment & 42 & 29.8 \\
\hline Development of dental product to help quit smoking & 18 & 12.8 \\
\hline
\end{tabular}


치과에서의 금연 치료의 효과에 관한 설문에서는 $18 \%$ 의 응답자만이 매우 효과적일 것이라고 답했으며, $70 \%$ 의 응답자가 약간 효과적이거나 보통일 것이라고 답했다(Fig. 2). 치과에서 금연 보조 약물 처방에 관해서 는 $20 \%$ 의 응답자가 매우 적절하다고 답했으며, $76 \%$ 의 응답자가 어느 정도 효과가 있을 것이라고 답했다(Fig. 3).
치과 금연치료 활성화를 위한 방안에 관한 복수응답 설문에서는 $46.3 \%$ 의 응답자가 구강 건강을 위해 금연 을 권장할 필요성이 있다고 답했으며, $29.8 \%$ 는 치과에 서의 금연치료에 대한 적극적인 홍보가 필요하다고 답 했다. 또한 $12.8 \%$ 는 치과적 보조 수단 개발이 필요하다 고 답했으며, $15 \%$ 에서는 치과의사의 금연 치료 전문 지 식 배양이 필요하다고 응답했다(Fig. 4).

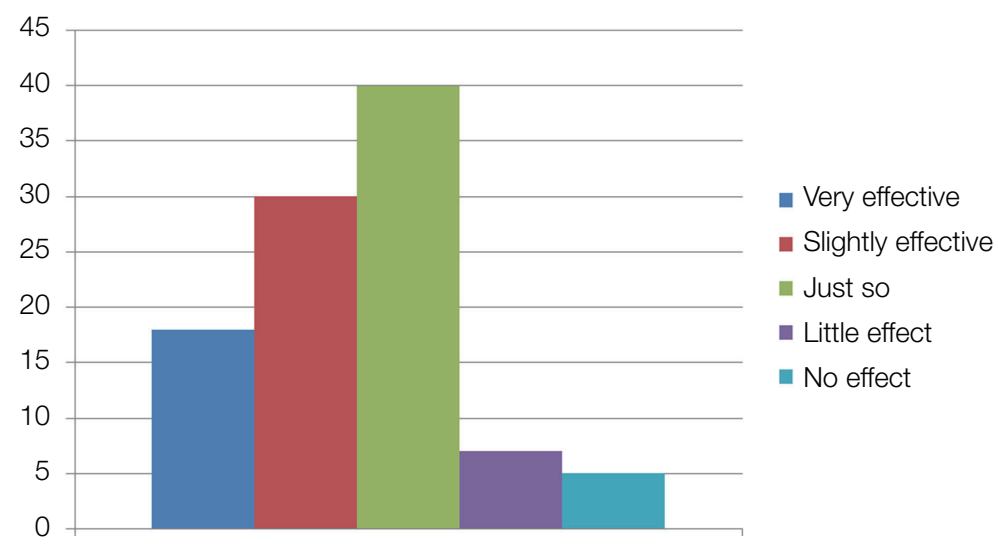

Fig. 2. Effectiveness of non-smoking treatment in dental clinic.

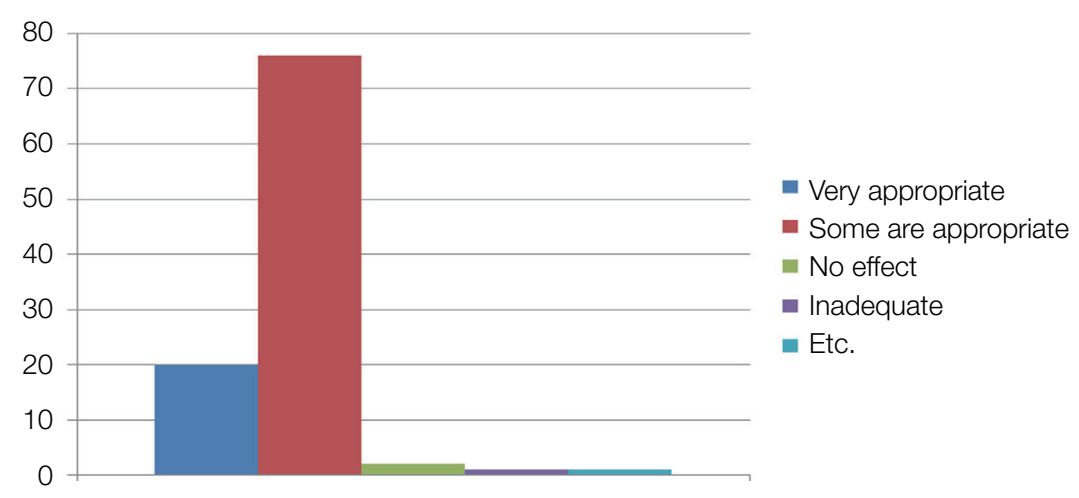

Fig. 3. Opinion about medication for smoking cessation in dentistry.

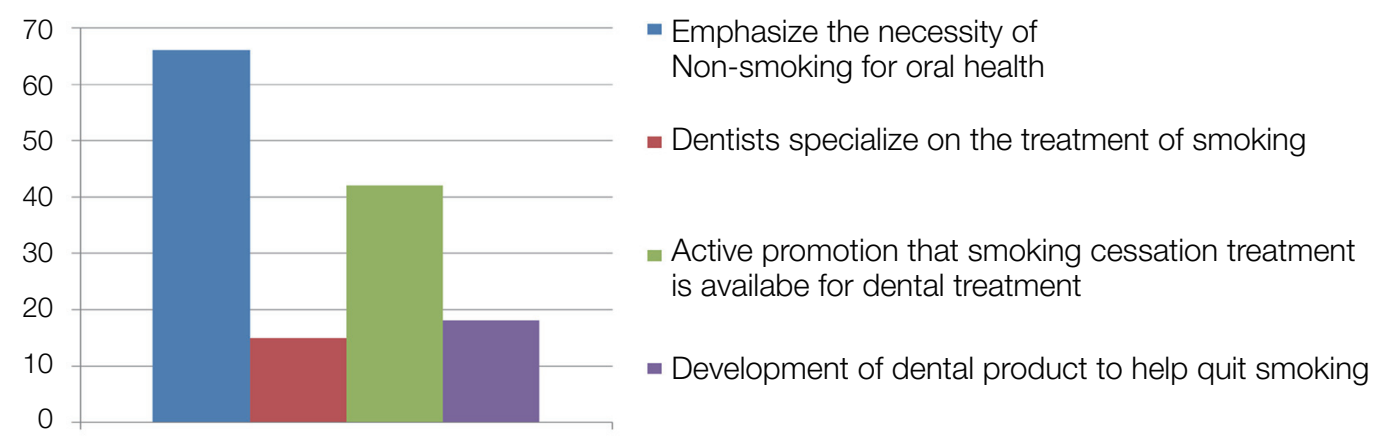

Fig. 4. How can activate the dental non-smoking treatment. 


\section{4. 금연 정책에 관한 인식 조사(Table 4)}

금연치료 비용에 관한 설문에서 $65 \%$ 의 응답자가 적 절하다고 답했으며, 비싸다고 생각하거나 $(18 \%)$, 저렴하 다고 생각한 군(17\%)의 비율은 유사하였다.

금연 치료에 대한 보건 복지 예산 증가 편성의 적절성 에 관한 설문에서는 $38 \%$ 의 응답자가 선진국형 보건 정 책이기 때문에 바람직하다고 답했으며, $31 \%$ 의 응답자 는 어느 정도 적절하다고 답했으며, $11 \%$ 의 응답자는 예 산의 축소가 필요하다고 답했다.

\section{고찰}

본 연구의 목적은 금연 진료에 대한 건강 보험이 치과 병원 및 치과의원 한의원까지 확대됨에 따라 환자들의 인식 수준이 어느 정도인지 알아보고 정책의 한계점을 분석하여 바람직한 정책의 시행방안을 제시하는 것이다.

설문 결과를 살펴보면 인구학적 조사에서 조사 대상 의 흡연율은 $18 \%$ 로 집계되었고 이는 우리나라의 일반 적 성인 흡연율인 약 $20 \%$ 보다 다소 낮은 수치이다. 이 는 영구치열기의 미성년 환자가 포함되었고, 대학병원 의 특성상 직장인의 접근성이 떨어지기 때문으로 사료 된다.

금연 지식 상태 조사에서 응답자의 과반수 $(52 \%)$ 는 금 연을 위한 전문적인 치료를 받을 수 있다는 사실을 모르 고 있었으며, 소수의 응답자 $(2 \%)$ 만이 치과의원에서의 금연 치료를 알고 있었다. 결국 대부분의 응답자 $(98 \%)$ 는 치과에서 금연을 위한 진료가 시행되었다는 사실을
모르고 있었으며, 이는 금연 치료 보험 확대의 이번 정 책 뿐만 아니라 종전의 금연 진료 정책에 있어서도 홍보 가 부족하였던 것으로 사료된다.

금연 치료에 적합하다고 생각하는 의료기관에 관한 설문에서는 치과의원이나 한의원보다는 병원급이나 내 과, 가정의학과 및 보건소가 높은 응답을 받았으며, 금 연 치료에 적절할 것으로 생각되는 인력이나 직종을 묻 는 설문에서는 금연 전문 상담사 및 의사를 선호하는 경 향을 보였다. 이는 종전의 금연 진료 정책의 대부분이 보건소에서 전문 상담사나 의사에 의해 이루어졌기 때 문으로 사료되며, 치과에서 금연진료를 하기 위해서는 정책 홍보 이외에도 치과의사의 금연 관련 진료 수행 능 력의 향상 또한 선행될 필요성이 있음을 시사한다.

치과 금연 치료에 관한 인식 조사 설문 결과에서도 비 슷한 결과를 보이는 부분이 있으며, 치과 에서의 금연 치료나 상담, 보조 약물 처방에 관해서도 많은 수의 응 답자들이 처음 듣거나 잘 모르고 있었다. 또한 치과에서 의 금연 치료에 관하여 많은 응답자 $(78 \%)$ 가 약간 효과 적, 보통, 효과 없음을 선택하는 등 진료의 효과에 대해 부정적으로 응답 하였다. 대부분의 응답자가 흡연과 치 과질환이 관련이 있다고 답한 것으로 보아 $(95 \%)$ 흡연이 구강 건강에 미치는 악영향에 대해서는 충분히 인지하 고 있는 것으로 사료되지만, 여러 설문 결과로 미루어보 아 현재로서는 금연을 위해 환자가 치과의원을 찾게 될 확률은 높지 않을 것으로 예상된다.

금연에 도움이 될 수 있는 방법에 관한 설문에서는 금 연 교육이 가장 많은 응답을 받았으며, 치과 금연 치료 활성화 방안으로는 구강 건강을 위한 금연의 필요성 강

Table 4. Survey on perception about non-smoking policy

\begin{tabular}{lcc}
\hline What do you think about treatment cost & Number $(\mathrm{n}=100)$ & Percentage $(\%)$ \\
Too expensive & 18 & 65 \\
It is appropriate & 18 & 65 \\
Cheap & Number $(\mathrm{n}=100)$ & Percentage $(\%)$ \\
\hline What is your opinion about increasing budget for health welfare & 38 & 38 \\
Very good & 31 & 31 \\
It is appropriate & 7 & 7 \\
Budgeting requires more money than now & 11 & 8 \\
It is a waste of budget & 8 & 8 \\
It is highly inappropriate & 5 \\
Etc. & 5 \\
\hline
\end{tabular}


조가 절반에 가까운 응답을 받았다(46.3\%). 이로 미루어 보아 금연을 위해서는 직접적인 치료보다는 교육을 통 한 의식 또는 의지의 개선이 중요하다고 여겨진다.

금연 치료에 대한 보건 복지 예산 증가 편성에 관해서 는 과반수의 응답자가 호의적인 반응을 보였으며(69\%), 금연 진료 비용에 관해서도 적절하다는 반응이었다.

이상의 설문 결과를 종합적으로 분석한 결과 환자들 은 흡연이 구강 건강에 해롭다는 것을 잘 알고 있지만, 치과나 치과 의사에게 금연 진료를 받는 것을 선호하지 는 않는 것으로 나타났다. 하지만 금연 진료에 관한 의 료 정책의 확대에 관해서는 전반적으로 긍정적인 반응 을 보이기 때문에, 정책을 축소하기보다는 이를 기회삼 아 발빠른 대처와 지속적인 노력으로 치과 진료 범위를 넓히는 것이 바람직해 보인다. 이를 위해 적극적인 홍보 로 금연 환자의 치과 방문을 장려하고, 이와 함께 금연 환자가 치과를 방문했을 경우 금연 성공률을 높여 줄 수 있는 전문적인 상담 능력을 배양하거나 혹은 상담 보조 인력를 양성하는 등 내실을 키울 수 있는 치과계의 세부 적인 노력이 시급할 것으로 사료된다.

\section{결론}

설문조사 결과 이번에 시행된 금연진료의 보험 확대 정책은 긍정적인 반응을 얻고있는 것으로 나타났으나, 대국민 홍보와 정책의 세부적인 시행에 있어서는 아직 미흡한 점이 많은 것으로 드러났다. 이를 개선하여 효율 적인 정책의 시행을 위해서는 보다 적극적인 홍보 등을 비롯한 정책적인 노력과 의료진의 자질 향상 등의 개인 적인 노력이 복합적으로 필요할 것으로 사료된다.

\section{Acknowledgements}

이 논문은 2011년도 정부(교육부)의 재원으로 한국 연구재단의 지원을 받아 수행된 기초연구사업임(No. 2011-0010739).

\section{Orcid}

Jung-Chul Park http://orcid.org/0000-0002-2041-8047

Hyun-Seung Shin http://orcid.org/0000-0002-1410-9731

In-Woo Cho http:// orcid.org/0000-0003-4985-3816

\section{References}

1. Korea Central Cancer Registry, National Cancer Center. Annual report of cancer statistics in Korea in 2012. Ministry of Health and Welfare; 2014. p. 12-23.

2. Seol SY, Lee SJ, Jeong MH, Rhee JA, Choi JS, Hwang SH, Ko JS, Lee MG, Sim DS, Park KH, Yoon NS, Yoon HJ, Kim KH, Hong YJ, Kim JH, Ahn Y, Cho JG, Park JC, Kang JC. Clinical outcomes of persistent smoking in patients with acute myocardial infarction who underwent percutaneous coronary intervention. Korean J Med 2011;80:562-70.

3. Degens H, Gayan-Ramirez G, van Hees HW. Smoking-induced skeletal muscle dysfunction: from evidence to mechanisms. Am J Respir Crit Care Med 2015;191:620-5.

4. Asfar T, Lam BL, Lee DJ. Smoking causes blindness: time for eye care professionals to join the fight against tobacco. Invest Ophthalmol Vis Sci 2015;56:1120-1.

5. Liebrechts-Akkerman G, Lao O, Liu F, van Sleuwen BE, Engelberts AC, L'hoir MP, Tiemeier HW, Kayser M. Postnatal parental smoking: an important risk factor for SIDS. Eur J Pediatr 2011;170:1281-91.

6. Korean Dental Association. Dental smoking cessation treatment guide book. Seoul; KDA; 2011. p. 4-10.

7. Doll C, Nack C, Raguse JD, Sticker A, Duttenhoefer F, Nelson K, Nahles S. Survival analysis of dental implants and implant-retained prostheses in oral cancer patients up to 20 years. Clin Oral Investig 2015;19:1347-52.

8. Kotsakis GA, Javed F, Hinrichs JE, Karoussis IK, Romanos GE. Impact of cigarette smoking on clinical outcomes of periodontal flap surgical procedures: a systematic review and meta-analysis. J Periodontol 2015;86:254-63.

9. Hwang JM, Kim EG, Cho YS, Park YD. Estimation of socioeconomic costs on smoke-related oral diseases. J Korean Acad Oral Health 2010;34:613-20.

10. Song MT. Changes in smoking rates of male adults in Korea and smoking cessation policy: focus on smoking cessation clinics. Health and Welfare Policy Forum 2011;3:55-63. 


\section{치과내 금연치료 건강보험 적용에 관한 환자 인식도 및 의식 수준에 관한 연구}

\section{조인우, 신현승*, 박정철}

단국대학교 치과대학 부속치과병원 치주과학교실

목적: 최근 들어 치과에서의 금연치료가 국민건강보험의 적용을 받게 되었다. 하지만 이에 관한 대국민 홍보나 국민들 의 인식은 충분하지 못할 것으로 예상된다. 그래서 본 연구에서는 치과 금연치료의 국민건강보험 적용에 관한 환자의 인식도 및 의식 수준에 관하여 조사해 보았다.

연구 재료 및 방법: 실험은 설문조사를 통하여 이루어졌으며, 2015년 3월에 단국대학교 치과대학 부속 치과병원에 내 원한 100 명을 대상으로 하였으며 18 개의 문항의 설문지를 개발하여 시행하였다.

결과: 설문 결과 응답자의 많은 수는 치과 금연치료에 관해 긍정적인 반응을 보였으나, 정책의 시행 사실이나 내용에 관한 지식 및 인식이 상당히 부족한 것으로 나타났다.

결론: 정부와 보건복지부 당국은 새로 시행된 이번 정책의 효율성을 높이기 위해 보다 많은 홍보 활동 등의 노력이 필 요할 것으로 사료되었다.

(구강회복응용과학지 2015;31(3):195-202)

주요어: 금연; 건강보험; 치과

*교신저자: 신현승

(31116) 충남 천안시 단대로 119 단국대학교 치과대학 치주과학교실

Tel: 041-550-0261 || Fax: 0303-3442-7364 | E-mail: perioshin@dankook.ac.kr

접수일: 2015년 6월 22일 | 수정일: 2015년 7월 14일 | 채택일: 2015년 7월 14일 